When my supervisor dislikes you more than me: The effect of dissimilarity in leadermember exchange on coworkers' interpersonal emotion and perceived help

(In press in the Journal of Applied Psychology)

\author{
Herman H. M. Tse \\ Griffith Business School \\ Griffith University \\ Brisbane, Nathan, QLD 4111, Australia \\ Office Phone No: 617 3735-7305 \\ Office Fax No: 617 3735-7988 \\ Email: h.tse@griffith.edu.au \\ Catherine C. K. Lam \\ Department of Management \\ City University of Hong Kong \\ Kowloon Tong, Hong Kong, China \\ Office Phone No: 852 3442-6209 \\ Office Fax No: 852 3442-0309 \\ Email: mg.cat@cityu.edu.hk
}

Sandra A. Lawrence

Center for Work, Organization and Well-Being

Griffith University

Brisbane, Nathan, QLD 4111, Australia

Office Phone No: 617 3735-7132

Office Fax No: 617 3735-4298

Email: s.lawrence@griffith.edu.au

$$
\text { Xu Huang }
$$

Department of Management and Marketing

Hong Kong Polytechnic University

Hung Hum, Hong Kong, China

Office Phone No: 852 2766-7388

Office Fax No: 852 2365-8645

Email: xu.huang@polyu.edu.hk 
LMX dissimilarity and coworkers' interpersonal emotion

\title{
When my supervisor dislikes you more than me: The effect of dissimilarity in leader- member exchange on coworkers' interpersonal emotion and perceived help
}

\begin{abstract}
According to balance theory (Heider, 1958), when two coworkers develop different levels of leader-member exchange (LMX) relationships with their supervisor, a triadic relational imbalance will arise among the three parties that may result in hostile sentiments and poor social interactions between them. This study examines the consequences and psychological processes of (dis)similar levels of LMX on the interpersonal interactions between coworkers. Using data from two independent studies, the results of social relations analyses show that (1) actual (dis)similarity in LMX between coworkers A and B increases A's feelings of contempt for B and decreases A's perception of help received from B (Study 1); (2) A is more likely to experience contempt for B when A perceives that he/she has a higher or lower level of LMX compared to B than when A perceives that his/her level of LMX is similar to B's (Study 2); and (3) these relationships only hold true for employees with a high social comparison orientation (SCO) in both Studies 1 and 2. Particularly, in Study 1, we also show that contempt is a crucial mediator that transmits the interactive effect of LMX (dis)similarity and SCO on perceptions of help received from coworkers. Furthermore, an average level of perceived help from coworkers is positively related to the sales performance of individual employees.
\end{abstract}

Keywords: Leader-member exchange (LMX), social comparison orientation (SCO), contempt, helping behavior, coworker dyads 
LMX dissimilarity and coworkers' interpersonal emotion

\section{When my supervisor dislikes you more than me: The effect of dissimilarity in leader- member exchange on coworkers' interpersonal emotion and perceived help}

Leader-member exchange (LMX) theory emphasizes that leaders develop a differential quality of dyadic relationships with followers such that within work groups, they form lowquality transactional relationships with some and high-quality socioemotional relationships with others (Dansereau, Graen, \& Haga, 1975). Previous research has demonstrated that LMX quality has strong implications for employees' work attitudes and behaviors (see Gerstner \& Day, 1997; Ilies, Nahrgang, \& Morgeson, 2007; Rockstuhl, Dulebohn, Ang, \& Shore, 2012). This research has particularly focused on the positive effects of LMX on vertical dyadic partners. However, our everyday experiences often highlight its negative effects: When a leader has a better quality of LMX with, and thus provides more support and resources to, subordinate A than to subordinate $\mathrm{B}$, the different exchange qualities of the two supervisor-subordinate dyads may have detrimental effects on the relationship of the third subordinate-subordinate dyad. To date, research on the potentially adverse impact of LMX beyond the leader-member dyad remains sparse (e.g., Henderson, Wayne, Shore, Bommer, \& Tetrick, 2008; Vidyarthi, Liden, Anand, Erdogan, \& Ghosh, 2010). Therefore, the main contribution of this study is to increase our understanding of the negative consequences of LMX dissimilarity on coworker interactions.

Drawing primarily on balance theory (Heider, 1958), we propose that dissimilarity in LMX between two supervisor-subordinate dyads will create relational imbalance in the triadic relationships among the supervisor and the two subordinates. Such triadic relational imbalance may provoke "hostile" interpersonal emotions (such as contempt, Heider, 1958, p. 190) between the subordinates, which in turn, will make each subordinate perceive the other as being less helpful. By contrast, similarity in LMX may reduce contempt and increase perceptions of 
LMX dissimilarity and coworkers' interpersonal emotion

interpersonal help. Figure 1 depicts our theoretical model. Investigating the effect of LMX (dis)similarity on coworkers' interpersonal emotions and perceived interactions is theoretically important because these emotions and perceptions have been shown to have implications for both intrapersonal (e.g., work motivation and effort intensity; Dirks, 1999) and interpersonal (e.g., trust, commitment, and conflict; see Reis \& Collins, 2000; helping behaviors; see Van der Vegt, Bunderson, \& Oosterhof, 2006) outcomes that ultimately determine how well teams function (Tse, Dasborough, \& Ashkanasy, 2005). Our study also adds value to the existing LMX research by showing that perceptions of poor interactions resulting from the (dis)similarity in coworkers' LMX may hinder the performance of individuals over time.

Building on social comparison theory (Festinger, 1954), we further extend and enrich balance theory by proposing and examining the social comparison processes that underlie and shape the degree of influence of the relational balance/imbalance in a triad in two independent studies. In Study 1, we indirectly infer the operation of social comparison by examining the interactive effect of coworker A's and coworker B's LMX on A's contempt for B in order to demonstrate how (dis)similarity in levels of LMX leads to interpersonal "hostile" emotions (Heider, 1958, p. 190). Moreover, in Study 2, we directly assess the operation of social comparison by measuring A's comparison of his/her LMX with that of B and how such a comparison is related in a U-shaped curvilinear fashion to A's contempt for B. In addition, we qualify this effect of comparison processes by investigating the moderating role of individual employees' social comparison orientation ( $\mathrm{SCO}$; that is, having a strong tendency to compare one's status with that of others; Gibbons \& Buunk, 1999) in both studies.

In a nutshell, the present article contributes to the literature by examining the detrimental consequences of leaders' differential exchange relationships with their subordinates on the 
LMX dissimilarity and coworkers' interpersonal emotion

interpersonal interactions between subordinates in work groups, by revealing how and when LMX (dis)similarity will have an impact on perceptions of received help, and by extending balance theory through testing social comparison explanations for the effect of triadic relational imbalance.

\section{Theory and Hypothesis Development}

\section{Balance Theory and Social Comparison}

The LMX literature suggests that interpersonal exchange relationships between supervisors, subordinates, and coworkers are interrelated and embedded within work groups (Henderson et al., 2008; Venkataramani, Green, \& Schleicher, 2010; Vidyarthi et al., 2010). The exchange quality of one dyad, however, can influence the relationship quality developed in the other two dyads (Graen \& Uhl-Bien, 1995). This triadic relationship can be explained by balance theory (Heider, 1958). A balanced triadic relationship occurs when both subordinate A and subordinate B form the same positive (or negative) relationship with supervisor C. In such a triad, both subordinates tend to experience a harmony that induces more positive and less negative sentiments toward each other. All other combinations of triadic relationships lead to relational imbalance and will therefore trigger negative sentiments (e.g., emotions, attitudes).

We contend that the psychological process causing such a relational balance or imbalance in triads is social comparison. Researchers in social psychology and social structure have suggested that people are aware of the patterns of surrounding social ties (Freeman, Freeman, \& Michaelson, 1988; Heider, 1958). In particular, in a mutually shared environment (i.e., a work group), people can detect the social relationship structure in order to obtain social comparison information that will help them to understand their relative standing in the group (Hogg, 2000; Wood, 1996). Consistent with this assumption, LMX scholars have also suggested that 
LMX dissimilarity and coworkers' interpersonal emotion

individual members are aware, through observations and nonverbal communications, of the LMX quality of each peer-leader relationship (Duchon, Green, \& Taber, 1986; Tse, Ashkanasy, \& Dasborough, 2012; Vidyarthi et al., 2010). Along with this line of research, affective events theory (AET; Weiss \& Cropanzano, 1996; Ashton-James \& Ashkanasy, 2008) and emotion research (Elfenbein, 2007) suggest that when the immediate work environment includes other people (Elfenbein, 2007), carries important social cues (Stratton, 2005), or provides social comparison information (Greenberg, Ashton-James, \& Ashkanasy, 2007; Spence, Ferris, Brown, \& Heller, 2011), it is likely to have a salient impact on the individual's emotional experiences with others. Therefore, the actual (dis)similarity of coworkers' LMX may trigger comparative evaluation processes between them which in turn will influence interpersonal sentiments. Accordingly, Heider (1958) has suggested that it is reasonable to expect actual similarity in certain traits and qualities (such as LMX) to be associated with coworkers' sentiments.

Only one study to date has used balance theory to understand LMX in a triadic leadercoworker relationship. Sherony and Green (2002) have demonstrated that two subordinates will develop positive coworker exchange quality (CWX) when they have similar LMX experiences. By contrast, two subordinates will have a negative CWX if they form dissimilar LMX with their leader. Their study provides insights into the impact of LMX (dis)similarity on the quality of coworkers' relationships and attitudes (e.g., work commitment and satisfaction). However, what Sherony and Green did not specifically explore is whether, and if so how, LMX (dis)similarity influences interpersonal emotion exchanges between subordinates. Indeed, the original hypothesis of balance theory focuses on how the degree of balance in a triad broadly influences interpersonal sentiments (Heider, 1944; 1946). Sentiment here refers to the way one person feels about or evaluates another. Specifically, relational imbalance in a triad may elicit negative 
LMX dissimilarity and coworkers' interpersonal emotion

sentiments, including "disliking and hostile feelings" directed at the interacting target (Heider, 1958, p. 190). Therefore, in the present study, we investigate how LMX (dis)similarity can influence subordinates to experience a hostile interpersonal emotion, namely contempt (i.e., anger, disgust, hatred; Fiske, Cuddy, Click, \& Xu, 2002) toward each other.

Contempt has been defined as an "exclusively social emotion" (Hess, 2009, p. 100; Roseman, 2001) which is often targeted toward members who have violated the social norms of hierarchical relations (Melwani \& Barsade, 2011; Rozin, Lowery, Imada, \& Haidt, 1999). Contempt typically conveys a sense of disapproval, psychological detachment, social exclusion and a negative view towards the interacting target (e.g., Fischer \& Roseman, 2007; Melwani \& Barsade, 2011). It may be the most theoretically relevant emotion to understanding the consequences of triadic imbalance. Balance theory (Heider, 1958) suggests that a harmonious, balanced relationship reflects "the requirement of justice" (p. 235), implying that the quality of hierarchical relations among two individuals in a triad is expected to be equal (as reflected by the LMX similarity). In contrast, any individual who deviates from such equitable communal relationships deserves to be disapproved of, socially excluded, and negatively evaluated typically expressed in the emotional form of contempt. In line with balance theory, the emotion literature has linked contempt with the perceived violation of communal codes such as the integrity of the social order and the expected equity in a hierarchy (Rozin, Lowery, et al. 1999). In particular, research has highlighted that contempt often occurs in competitive relationships (Fiske et al., 2002; Hutcherson \& Gross, 2011). Given that a coworker who has dissimilar LMX violates an actor's expectation of balanced hierarchical relations and the unequal LMX status also indicates that two coworkers are competing for the benefits of a high-quality exchange 
LMX dissimilarity and coworkers' interpersonal emotion

relationship with a leader (Erdogan \& Bauer, 2010), an actor's contempt toward the target coworker is likely to be triggered.

Based on balance theory, we argue that coworker A will experience more contempt toward coworker B if both coworkers have different levels of LMX with their supervisor. The dissimilarity in coworkers' LMX (i.e., if A's LMX is high and B's is low or if A's LMX is low and B's is high) reflects the difference in the coworkers' standing in the triad and may drive the individual to contrast him/herself with the comparison target coworker and focus on the distinguishing features of the target. Such a contrastive comparison may activate an independent self/differentiation mindset, highlighting the self-other LMX discrepancy and relational imbalance and exacerbating the levels of psychological discomfort and tension (Aron, Aron, Tudor, \& Nelson, 1991; Byrne, 1971; Shah, 2003).

Furthermore, the differentiation mindset activated by LMX dissimilarity may enact the two social-distancing functions of contempt: excluding the low LMX coworker from social relationships and reducing the status of the high LMX coworker (Melwani \& Barsade, 2011). Experiencing contempt for a low LMX coworker implies the accompanying cognitions that the coworker is inferior, weak, and unimportant and has failed to meet the interpersonal standards required to be included in the in-group (Ekman, 1994; Fischer \& Roseman, 2007). When interacting with a high LMX coworker, experiencing contempt can trigger perceptions of strength and superiority over the other, boosting one's status and weakening the superior status enjoyed by the high LMX coworker (Keltner \& Haidt, 1999). In both ways, contempt helps the actor to safeguard his/her status and defend him/herself from feelings of inferiority and thus reestablish the psychological social balance in the triadic leader-member relationship (Melwani 
LMX dissimilarity and coworkers' interpersonal emotion

$\&$ Barsade, 2011). In sum, the actor's contempt will be experienced toward a fellow coworker who has a better or worse relationship with a leader (i.e., LMX dissimilarity).

By contrast, coworker A would feel less contempt for B if both have a similar level of LMX (either high or low) with their supervisor. The similar LMX signals that both have a similar standing in the triad. Hence, in the comparison process, the focal employee will focus more on the commonalities between him/herself and the target, triggering feelings of attraction, closeness, and harmony. This relational balance will consequently activate shared schemas that increase relational identification (Aron et al., 1991; Shah, 2003). Such an assimilation effect may suppress the formation of a negative impression and thus reduce A's contempt for B.

\section{The Moderating Role of Social Comparison Orientation (SCO)}

Given that the balance dynamic is inherently linked to the process of social comparison, a more complete understanding of the effect of LMX (dis) similarity requires consideration of the SCO of the interacting actors. SCO is a dispositional factor representing individuals' inclination to compare their accomplishments, experiences, and situations with those of others (Gibbons \& Buunk, 1999). Likewise, the recent development of AET highlights the importance of understanding how social comparison processes operate in a complex work environment (such as leader-coworker triadic relationships) to generate emotions and the role of individual disposition in these processes (Greenberg et al., 2007). Based on these ideas, we propose that SCO will moderate the effect of LMX (dis)similarity on contempt.

Individuals with high SCO are sensitive to the behavior of others and have a tendency to reduce uncertainty about their self-concept by actively engaging in self-affirmation (Buunk \& Mussweiler, 2001; Bunnk, Zurriaga, Peiro, Nauta, \& Gosalvez, 2005; Gibbons \& Buunk, 1999). Research shows that high-SCO individuals, who usually have low self-esteem and strong self- 
LMX dissimilarity and coworkers' interpersonal emotion

consciousness, are more inclined to engage in comparison with other coworkers (Buunk \& Gibbons, 2007). On this basis, we argue that individuals with high SCO are more likely to experience a heightened emotional reaction to the LMX (dis)similarity in triads than those with low SCO because they are more sensitive to their relative standing with respect to their own LMX in relation to that of other coworkers. As a consequence, a high-SCO individual will experience more contempt for another coworker in a triad when they have dissimilar LMX, while relatively less contempt will be experienced when their LMX is seen to be similar. In contrast, low-SCO individuals have relatively high self-esteem, strong self-consciousness, and low neuroticism and do not tend to rely on social comparisons to obtain a good selfunderstanding (Buunk \& Gibbons, 2007; Buunk et al., 2005; Gibbons \& Buunk, 1999). Accordingly, a low-SCO individual is less sensitive to the (dis)similarity in LMX within a triad and so is less likely to experience contempt for the coworker. Therefore, for a low-SCO individual, LMX (dis)similarity will be less strongly related to contempt.

Taken together, the effect of LMX (dis)similarity on contempt is expected to be attenuated when SCO is lower and amplified when it is higher. Hence, we propose the following hypothesis:

Hypothesis 1: SCO moderates the impact of (dis)similarity of coworkers' LMX on interpersonal contempt. That is, when SCO is high, the LMX (dis)similarity between two coworkers (increases) decreases coworker A's contempt for coworker B. When SCO is low, the LMX (dis) similarity between two coworkers is less related to coworker A's contempt for coworker B. 
LMX dissimilarity and coworkers' interpersonal emotion

\section{Contempt and Perceptions of Received Help}

We further propose that contempt will be negatively associated with perceptions of received help (i.e., an individual's perception of whether or not a coworker has voluntarily helped him/her to deal with work-related tasks or personal problems; Settoon \& Mossholder, 2002). According to Schwarz and Clore (1996), individuals often rely on emotional states to guide their thoughts, judgments, and evaluations. More importantly, emotions can substantially bias individuals' access to and use of the thoughts, ideas, memories, and interpretations (Forgas, 2002) that influence their information processes, attitude formation, and categorical evaluations of others (Forgas \& Smith, 2003). Recent research has also demonstrated that individuals (actors) tend to evaluate a target more positively or negatively and categorize the target as more or less helpful depending on their emotional states (Krosnick, Betz, Jussim, \& Lynn, 1992; Petty, 1995). In particular, it has been shown that hostile emotions (e.g., contempt) evoke tension and disliking (Roseman, 2001) and also trigger negative perceptions about a target's behavior (Silvester, 1997). In addition, contempt is associated with seeing the target as unfriendly and lacking warmth (Cuddy, Fiske, \& Glick, 2007) and therefore negatively biases perceptions of receiving help from the target (Lyons \& Scott, 2012). The above discussion leads to the following hypothesis:

Hypothesis 2: The interpersonal emotion of contempt experienced by coworker A toward coworker $B$ is negatively related to A's perception of help received from $B$.

\section{The Mediating Role of Contempt}

The above consideration sketches a complex picture of the consequences of relational (im)balance in a triad. We argue that LMX (dis)similarity may interact with SCO to trigger feelings of contempt between subordinates. Contempt, in turn, may also influence coworkers' 
LMX dissimilarity and coworkers' interpersonal emotion

perceptions of the help they get from each other (Lyons, \& Scott, 2012; Neuberg \& Cottrell, 2002). Taken together, it is logical to predict a conditional indirect relationship. This prediction is in line with the AET framework (Weiss \& Cropanzano, 1996). AET suggests that discrete emotion helps individuals interpret the meaning of environmental cues, determining their judgment formation and the behavioral consequences. Following this logic, we propose that contempt will transmit the indirect effect of LMX (dis)similarity on perceptions of received help and that the strength of this indirect linkage will hinge on the level of SCO. Specifically, a highSCO individual is likely to experience less (more) contempt toward another coworker in a triad if their levels of LMX are similar (dissimilar), therefore increasing (decreasing) their perceptions of help received from the coworker. By contrast, low SCO may help to mitigate the indirect effect of LMX (dis)similarity on perceptions of received help because a low-SCO individual is less emotionally sensitive to the social comparison information in the LMX processes.

In sum, the positive and negative indirect linkages between LMX (dis)similarity and perceptions of received help, as mediated by contempt, should be more pronounced when SCO is high rather than low. Hence, we propose the following hypothesis:

Hypothesis 3: The LMX (dis)similarity between coworkers A and B is (negatively) positively and indirectly related to A's perception of help received from $B$ (through contempt). These indirect relationships are more pronounced when SCO is high rather than low.

\section{Perceptions of Received Help and Individual Performance}

Given that perceptions of received help have not been commonly theorized and tested as an outcome variable in the literature (see de Jong, Van der Vegt, \& Mollenman, 2007; Lyons \& Scott, 2012), it is important to explore their implications for individuals' work behaviors. Halbesleben (2006) suggests that when individuals perceive that their coworkers are not willing 
LMX dissimilarity and coworkers' interpersonal emotion

to help them, this represents a lack of support or a threat of resource loss which motivates them to protect their resources by withdrawing from work and reducing their performance levels (Venkataramani \& Dalal, 2007). In contrast, the perception that one is receiving help from coworkers can increase one's willingness to work with others and exchange information and resources that may facilitate effective work performance (Lee \& Ashforth, 1996). This line of reasoning suggests that the degree to which a member, on average, perceives that he/she has received more help from other team members will be positively related to his/her performance. Thus, we propose the following hypothesis:

Hypothesis 4: A team member's average level of perception of perceived help is positively related to his/her individual performance.

\section{Study 1: Method}

\section{Respondents and Procedure}

The sample for this study consisted of sales associates and their team members within a large telecommunication services company in China. Two types of data were collected to test our hypotheses. All of the respondents were first asked to respond to items measuring their individual LMX and SCO as well as several control variables. They were then asked to provide responses to social network items assessing their contempt for specific coworkers in dyads within work groups and their perceptions of the help received from these coworkers using a round-robin design (Warner, Kenny, \& Stoto, 1979). To meet the design requirements, we selected teams with at least four members (a maximum of five). In a team of four, each individual rated three targets, and so 12 direct assessments of contempt and perceptions of received help were obtained. These round-robin peer-rating data were then matched to an individual's responses on LMX, SCO, sales performance, and the control variables. The data of 
LMX dissimilarity and coworkers' interpersonal emotion

12 dyads were removed because their questionnaires were incomplete. Therefore, the final sample for this study consisted of 408 dyadic relationships (from 128 individuals in 31 work groups), yielding an effective response rate of $97 \%$. The mean age and organizational tenure of the respondents were 25 and 1.2 years, respectively. Forty-four percent of them were female, and $44 \%$ had a high school education or above. The average length of the dyadic relationships was 5 months.

\section{Measures}

All of the measures used in this study were developed originally in English and subsequently back-translated into Chinese by bilingual experts to obtain semantic equivalence and agreement (Brislin, Lonner, \& Thorndike, 1973).

\section{Individual-level Measures}

Control variables. We controlled for the demographic variables of gender, age, dyadic tenure, and team size because these variables have been shown to influence group processes (Richter, West, van Dick, \& Dawson, 2006). We also controlled for actors' positive and negative affectivity using the Positive and Negative Affect Scale (PANAS; Watson, Clark, \& Tellegen, 1988) because these personality traits may have confounding effects on contempt. The respondents indicated how they generally felt with regard to particular positive and negative emotions.

LMX (dis)similarity. We used the LMX-7 scale developed by Scandura and Graen (1984) and adapted by Graen and Uhl-Bien (1995) to measure an individual's perception of the quality of the exchange relationship with his/her supervisor in a work group. This scale consists of seven items. A sample item is "How would you characterize your working relationship with your leader?" ( 1 = extremely ineffective, $5=$ extremely effective $)$. Because of the potential 
LMX dissimilarity and coworkers' interpersonal emotion

problems associated with the use of different scores (Edwards, 1994; 2001), we followed previous research (de Jong et al., 2007; Huang \& Iun, 2006; Van der Vegt et al., 2006) and used the interaction term between the LMX scores for coworkers A and B to reflect the nature of the (dis)similarity of their LMX.

Social Comparison Orientation (SCO). We adapted 11 items from the SCO scale developed by Gibbons and Buunk (1999) to measure this construct. This scale is designed to measure the extent to which individuals make comparisons between their opinions, abilities, and general aspects of their selves and those of others on a 5 -point scale $(1=$ strongly disagree $; 5=$ strongly agree). A sample item is "I always pay a lot of attention to how I do things compared with how my coworkers do things."

Sales performance. We obtained monthly sales records (number of telecommunication services packages sold) from the company for all respondents one month after the paper surveys had been collected.

\section{Dyadic Measures (round-robin peer-rating)}

We measured contempt and perceptions of received help in coworker dyads. Following previous research using a round-robin design (e.g., de Jong et al., 2007; Venkataramani \& Dalal, 2007), we used an abbreviated version of the measures for both constructs based on a pilot study. ${ }^{1}$ Items were selected for the present study if they had a factor loading of .80 or higher on their respective factors in a confirmatory factor analysis.

Contempt. We adapted three hostile emotion items (i.e., angry, disgusted, and hateful) from Fiske et al.'s (2002) scale to measure contempt using a 5-point scale $(1=$ never, $5=$ always). The respondents consecutively indicated how often they experienced the respective emotions with each of their fellow team members.

\footnotetext{
${ }^{1}$ Sample details of the pilot study can be made available upon request.
} 
LMX dissimilarity and coworkers' interpersonal emotion

Perceptions of received help. We adapted three items from Settoon and Mossholder (2002) to assess person-focused interpersonal help received from other coworkers. These three items were used by de Jong et al. (2007) to reflect the dyadic level of analysis. Each respondent was asked to rate the extent to which each of their fellow teammates intentionally engaged in activities to help him or her on a 5-point scale $(1=$ strongly disagree; $5=$ strongly agree $)$. A sample item was "[X] takes time to listen to my problems and worries."

\section{Results}

\section{Confirmatory Factor Analyses (CFAs)}

Before testing the hypotheses, we first conducted a set of CFAs to evaluate the discriminant validity of the two peer-rated variables (contempt and perceptions of received help). The results showed that the hypothesized two-factor model $(C F I=.99, G F I=.98, R M S E A=.05)$ yielded a better fit than the one-factor model, with a change in chi-square $\left(\Delta \chi^{2}(1)=634.95, p\right.$ $<.01)$. Finally, we confirmed the overall hypothesized measurement model by loading each item onto its respective factor (i.e., LMX, SCO, contempt, and perceptions of received help). We also compared the chi-square and fit indices of our hypothesized four-factor model to the one-factor model. Again, the latter did not fit the data well $(C F I=.36, G F I=.68, R M S E A=.19)$, whereas our hypothesized measurement model fitted the data significantly better $(C F I=.95, G F I=.93$, $R M S E A=.05)$, with a change in chi-square $\left(\Delta \chi^{2}(6)=1524, p<.01\right)$, than the other models. These CFA results provided support for the distinctiveness of the four variables for the subsequent analyses.

\section{Descriptive Statistics}

Table 1 presents the descriptive statistics, correlations, and reliabilities of all of the study variables. As shown in the table, coworker A's perception of received help from coworker B was 
LMX dissimilarity and coworkers' interpersonal emotion

positively related to A's LMX and negatively related to A's contempt for B. Furthermore, there was a positive bivariate relationship between perception of received help and sales performance.

\section{Analytical Strategy}

The round-robin data collected for the purpose of this study has a complex nested structure, with dyadic relationships with other members nested within individuals, and individuals nested within work teams. We therefore analyzed our multilevel model using social relations modeling (SRM; see Kenny, 1994; Kenny \& La Voie, 1984), which is a specific method for analyzing relational data in which the substantial portion of the variance in the dependent variables is located at the dyadic level (i.e., depends on the characteristics of the dyadic relations between actor and target; Kenny \& La Voie, 1984). The unique feature of SRM is to isolate variance in a social network and test hypotheses at multiple levels of analysis: actor (coworker A), target (coworker B), dyad (A and B's relationship), and group. Actor (or perceiver) variance is the proportion that arises from the tendency of an actor to rate all other members in a particular way. Target variance refers to the proportion arising from the tendency of a target to receive similar ratings from other members. Dyadic variance arises from the particular relationship between the perceiver and the target. Group variance arises from group membership, which is influenced by group norms (see Kenny, 1994; Kenny \& La Voie, 1984). This specific feature of SRM enables researchers to address questions about how much of the variance in dyadic variables is due to individual-level effects (e.g., LMX, dispositional characteristics, etc.) and how much comes down to questions about reciprocity or mutuality.

We used MLwin in conjunction with SRM to analyze our data (see Snijders \& Kenny, 1999 for technical details). MLwin helped to justify the multilevel structure of our data by distinguishing between different levels of analysis as well as between random and fixed effects 
LMX dissimilarity and coworkers' interpersonal emotion

estimates. The random effects estimates indicate the percentages of the total variance in an actor's (i.e., coworker A) contempt for, and perceptions of help received from, coworker B that are attributable to the characteristics of the actor, the target (at the individual level), the dyadic relationship, and the team. The fixed effect estimates indicate the strength of the relationship between the independent variables (i.e., the (dis)similarity in LMX between two coworkers and their SCO) and the dependent variables (i.e., A's contempt for, and perceptions of received help from, B). These estimates are comparable to the unstandardized regression coefficients in an ordinary least squares regression analysis and were used to test our study hypotheses (Snijders \& Kenny, 1999).

To conduct an SRM analysis, we first calculated a null model which was used to partition the variance of contempt and coworker A's perception of help received from coworker B into actor, target, dyadic, and team variance (see Table 2). Next, we used SRM to examine Hypotheses 1 and 2 (see Tables 3 and 4). We tested for a decrease in log-likelihood between each of the models described in Tables 3 and 4 by means of a chi-square difference test, evaluating the statistical significance of improvements in model fit. To test Hypothesis 3, we built on the procedure outlined by Krull and McKinnon (2001) to test the conditional indirect relationships. Firstly, we derived the simple slopes of the relation between the independent variable (B's LMX) and the mediator (A's contempt for B) at high (+1 SD) and low values (-1 $S D$ ) of the two moderators - A's LMX and SCO. We also drew on the relationship between contempt and perceptions of received help found when testing Hypothesis 2. Based on Selig and Preacher's (2008) Monte Carlo method, we then employed these estimates to derive percentile confidence intervals for the population values of the conditional indirect relationship between the independent (B's LMX) and dependent (A's perception of received help from B) variables, 
LMX dissimilarity and coworkers' interpersonal emotion

through the effect of the mediator (A's contempt for B), at high and low levels of the two moderators (A's LMX and SCO). The use of such confidence intervals is considered superior to traditional methods (e.g., the Sobel [1982] test) in examining (conditional) indirect relationships because it ameliorates the power problems introduced by non-normal sampling distributions of an indirect relation (MacKinnon, Lockwood, \& Williams, 2004).

Finally, following the analytical procedure outlined by Lam, Van der Vegt, Walter, and Huang (2011), we used ordinary hierarchical regression analysis to examine Hypothesis 4 because both the predictor (average perception of help received from teammates) and the outcome variable (individual sales performance) for this hypothesis were located at the same level of analysis (i.e., the individual level).

\section{Variance Partitioning}

Table 2 presents the partitioning of the variance in A's contempt for B and A's perception of the help received from B at the actor, target, dyadic, and team levels of analysis. As shown in Table 2, $61 \%$ of the total variance in contempt and $62 \%$ of the perceptions of received help were located at the dyadic level. These findings show that the specifics of the relationship between A and B have the strongest influence on contempt for, and perceptions of help received from, another teammate.

\section{Hypotheses Tests}

Hypothesis 1 predicted that SCO would moderate the effect of LMX (dis)similarity on interpersonal contempt. Statistically, we captured the LMX (dis)similarity between coworker A and coworker B in terms of the interaction of their LMX and then examined how SCO moderated the interactive effect of A's and B's LMX on A's contempt for B. As shown in Table 3, the three-way interaction term of A's LMX, B's LMX, and SCO was significantly associated 
LMX dissimilarity and coworkers' interpersonal emotion

with A's contempt for B (see Model 3; $B=-.08, p<.01$ ) after considering the control variables, main effects, and two-way interaction terms. Figure 2 illustrates the pattern of this interaction (Aiken \& West, 1991). As expected, under the condition of high SCO (see Figure 2a), higher B's LMX was associated with lower contempt toward B from A when A's LMX was high (i.e., similarity in LMX; simple slopes test: $B=-.14, S E=.07, p<.05)$. However, when A's LMX was low, higher B's LMX was positively related to A's contempt for B (i.e., dissimilarity in LMX; simple slopes test: $B=.14, S E=.07, p<.05)$. In contrast, under the condition of low SCO (see Figure 2b), B's LMX was unrelated to A's contempt for B at both low (simple slopes test: $B$ $=-.07, S E=.07, n . s$.$) and high (simple slopes test: B=.00, S E=.07, n . s$.$) levels of A's LMX.$ These results provide support for Hypothesis 1, showing that the more (less) similar the LMX experienced by two coworkers, the less (more) contempt a coworker may feel toward the other when SCO is high rather than low.

Hypothesis 2 predicted that A's contempt for B would be negatively associated with A's perception of the help received from B. As shown in Table 4, this relationship was indeed negative $(B=-.24, p<.01)$ even after incorporating several control variables, main effects, and the respective interaction terms. Hence, Hypothesis 2 received support.

Hypothesis 3 predicted that SCO would moderate the indirect relationship between LMX (dis)similarity and perceptions of received help as transmitted by contempt. Based on the analytical strategy outlined above, we inspected the conditional indirect relationship between B's LMX and A's perception of help from B at two levels of A's LMX and SCO, namely one standard deviation below and above the mean. The results are reported in the lower section of Table 4. When SCO was higher, the indirect relationship between B's LMX and A's perception of help from B (via A's contempt for B) was positive $(B=.04)$ when A's LMX was higher (i.e., 
LMX dissimilarity and coworkers' interpersonal emotion

similarity in LMX); it became negative $(B=-.04)$ when A's LMX was lower (i.e., dissimilarity in LMX), as indicated by both a significant Sobel test and a percentile confidence interval that excluded zero. In contrast, when SCO was lower, these indirect effects were insignificant regardless of A's LMX. Thus, Hypothesis 3 also received support.

To completely follow the spirit of balance theory, we also examined the reciprocal relationships between contempt and perceptions of received help between any two group members. We tested the dyadic reciprocations by computing within-dyad covariance divided by dyadic variance (Kenny, Kashy, \& Cook, 2006; Snijders \& Kenny, 1999). We found evidence for within-dyad reciprocity in levels of contempt $(r=.23, p<.05)$ and perceptions of received help $(r=.62, p<.01)$ between any two coworkers within any work group in our sample. These results suggest that contempt and perceptions of received help as triggered by (im)balanced LMX are reciprocated between two coworkers.

Finally, we tested Hypothesis 4, which looked at the relationship between perceptions of help received from coworkers and individual-level sales performance. Intra-class correlation and inter-rater reliability tests were conducted to identify the appropriateness of aggregating dyadiclevel perceptions of received help as an individual-level construct. The results of an analysis of variance (ANOVA) indicated that there was significant between-person variance in perceptions of received help $\left(F_{127,407}=2.71, p<.01\right)$. Table 2 also shows that $26 \%$ of the variance in perceptions of received help can be attributed to between-person differences (i.e., $\mathrm{ICC}_{1}$ ). Furthermore, both the reliability of individuals' mean ratings $\left(\mathrm{ICC}_{2}=.73\right)$ and the median within-individual agreement index for perceived receipt of help (median $r_{w g(j)}=.83$ ) exceeded the recommended values for construct aggregation (e.g., Bliese, 2000; James, Demaree, \& Wolf, 1984). Based on this statistical support, we aggregated the perception of received help as an 
LMX dissimilarity and coworkers' interpersonal emotion

individual-level construct representing the degree to which a person on average perceives him/herself as receiving help from other team members. We then standardized individuals' sales records (at Time 2 - a month after the surveys had been collected) and regressed this on the individual-level perceptions of received help (Time 1), controlling for team size and respondents' age, gender $(0=$ male, $1=$ female $)$, and organizational tenure. The results showed that the perception of received help from coworkers $(B=1.91, p<.05)$ was positively related to sales performance. This suggests that an individual's perception of the help received from other coworkers in a work group has a positive impact on his/her actual sales performance over time. Hypothesis 4 was therefore supported.

\section{Study 2}

In Study 1, we argued that the actual (dis)similarity in LMX (operationalized using the interaction term of two coworkers' LMX) between a focal employee and coworker influences the former's hostile feelings toward the latter. This is because the (dis)similarity in LMX may trigger social comparison processes among the interacting dyadic members. Although research suggests that an employee is constantly comparing and evaluating his/her relative LMX standing in a team (i.e., whether his/her LMX is higher or lower than a target coworker) and that this subjective comparison is highly correlated to objectively measured LMX (dis)similarity between coworkers (Vidyarthi et al., 2010), we did not measure and test these comparison processes in Study 1. Therefore, we also conducted Study 2 to directly measure the perceptual comparison of coworkers' $L M X$ by directly asking employees to compare their LMX with the LMX of each of their respective coworkers in their work group (i.e., LMX social comparison; Vidyarthi et al., 2010). We would expect the subjective comparison of LMX (LMXSC) to exert a similar influence on contempt as the objective LMX (dis)similarity explored in Study 1. 
LMX dissimilarity and coworkers' interpersonal emotion

More specifically, when an employee perceives that his/her LMX is better or worse than that of a target coworker, he/she is likely to be aware of the relational imbalance in the triad (i.e., the dissimilar level of LMX between him/herself and the target coworker), thus invoking a higher level of contempt for the target. However, when the employee perceives that his/her LMX is at a similar level to that of the target coworker (i.e., medium levels of LMXSC), he/she is likely to feel less contemptuous. Hence, LMXSC may have a U-shaped relationship with contempt, in that the latter will be highest at both the lowest and highest levels of LMXSC. Furthermore, in line with Hypothesis 1, we propose that such a U-shaped link between LMXSC and contempt will be stronger for employees with higher levels of SCO because they will be more sensitive to information about their comparative standing in the work group. By contrast, for employees with low levels of SCO, we predict that LMXSC will be less related to contempt. Accordingly, we propose the following hypothesis:

Hypothesis 5: SCO moderates the curvilinear relationship between LMXSC and contempt. That is, when SCO is high, coworker A experiences more contempt for B at both low and high (rather than medium) levels of LMXSC. When SCO is low, coworker A's LMXSC is less related to contempt for coworker $B$.

\section{Study 2: Method}

Data were collected from engineers working in $R \& D$ project teams in a high-technology company located in the southern part of China. The company's core business is developing new software and network designs for telecommunication services providers, local government, and businesses. Out of 70 questionnaires distributed, our final data set contained 68 individuals (260 dyadic relations) across 17 teams (96\% effective response rate). The mean age of the respondents was 26 , and the mean organizational tenure was 1.2 years; $29 \%$ of the respondents were female, 
LMX dissimilarity and coworkers' interpersonal emotion

and all respondents had a high school education or above. The average length of the dyadic relationships was 8 months. As in Study 1, respondents provided their self-ratings of SCO (Gibbons \& Buunk, 1999) and other control variables (gender, age, dyadic tenure, team size, and positive and negative affectivity; Watson et al., 1988). Ratings for LMXSC (Vidyarthi et al., 2010) and contempt (disgusted, contemptuous, hostile, and angry; $1=$ never; 5 =always; Fiske et al., 2002) were collected using a round-robin design. We used six items from Vidyarthi et al.'s (2010) scale to measure LMXSC. The respondents were asked to assess the quality of their relationship with their supervisor compared with that of each of their teammates on a 5-point scale $(1=$ strongly disagree $; 5=$ strongly agree $)$. A sample item was "I have a better relationship with my manager than $[\mathrm{X}]$.” Table 5 depicts the descriptive statistics, correlations, and reliabilities of all Study 2 variables.

\section{Results}

Before testing the hypothesis, we first conducted a CFA to evaluate the discriminant validity of our hypothesized measurement model (i.e., LMXSC, SCO, contempt). The results showed that the hypothesized three-factor model $(C F I=.91, G F I=.88, R M S E A=.08)$ yielded a good fit to the data that was substantially better than an alternative one-factor model $(C F I=.46, G F I=.58, R M S E A$ $=.19)$, with a change in chi-square $\left(\Delta \chi^{2}(3)=3209.91, p<.01\right)$. These findings supported the discriminant validity of the study variables. Secondly, we conducted variance partitioning for contempt. Table 6 shows that $24 \%$ of the total variance in contempt was located at the dyadic level. This indicates that a considerable portion of the variance in contempt depended on the characteristics of the dyadic relationship between actor and target.

Hypothesis 5 predicted that SCO would moderate the curvilinear relationship between LMXSC and contempt. As shown in Table 7 (Model 3), the interaction term of the squared 
LMX dissimilarity and coworkers' interpersonal emotion

LMXSC and SCO was significant for contempt $(B=.08, p<.05)$. We further examined the simple slopes of the regression curve corresponding to all possible combinations of high $(+1 S D)$, medium (mean), and low (-1 SD) levels of LMXSC with high and low levels of SCO (Aiken \& West, 1991). The results showed (see Table 8 and Figure 3) that in the case of high SCO, coworker A exhibited higher levels of contempt at both low and high levels of LMXSC. Increasing LMX similarity (ranging from low to medium LMXSC) was negatively related to contempt $(B=-.29, p<.05)$. After LMXSC had reached a medium level, increasing LMX dissimilarity (from medium to high LMXSC) was positively related to contempt $(B=.37, p$ $<.05)$. By contrast, when SCO was low, LMXSC was unrelated to contempt. These findings provided support for Hypothesis 5.

\section{Discussion}

In the present study, we have examined how LMX (dis)similarity between coworkers influences their feelings of contempt for, and perceptions of help received from, each other. Our results generally support the relationships hypothesized in our model (Figure 1). We highlight several important findings. First of all, we have demonstrated the role of LMX (dis)similarity in the development of interpersonal contempt in two independent studies. Specifically, we found that when SCO was high (rather than low), coworker A was more likely to feel contemptuous of coworker B when A's LMX was higher or lower than B's (Study 1) or when A perceived his/her LMX to be higher or lower than B's (Study 2). In addition, Study 1 further demonstrated the psychological processes and performance implications of LMX (dis)similarity. We found that the interactive effect between LMX (dis)similarity and SCO indirectly, via contempt, influenced perceptions of the help received from the coworker. Furthermore, the average level of received help was positively related to the sales performance of individual employees. 
LMX dissimilarity and coworkers' interpersonal emotion

\section{Theoretical Implications}

Our findings contribute to the literature in several ways. Although LMX theory has increased our understanding of how leaders contribute to individual employees' work attitudes and performance (see Gerstner \& Day, 1997 for a review), most of the empirical studies have typically treated each dyadic LMX relationship in isolation and overlooked its potential impact on the surrounding social context (Schriesheim, Castro, Zhou, \& Yammarino, 2001). In response to calls for research to examine the potential influences of LMX on the broader social networks of work groups (Henderson et al., 2008; Sherony \& Green, 2002; Sparrowe \& Liden, 1997; Tse et al., 2012), we attempted to go beyond the supervisor-subordinate dyads to investigate how different levels of LMX within a work group could undermine the interactions between in-group and out-group members. Our findings suggest that LMX dissimilarity is likely to induce hostile interpersonal emotions between coworkers that may have a negative impact on their perceptions of the help received from each other. Since they are less likely to experience help and support from coworkers with different LMX levels, the ultimate consequence is decreased performance.

Second, we extend balance theory (Heider, 1958) by examining the social comparison mechanisms that provide more nuanced explanations for the dynamics of triadic relationships among coworker A, coworker B, and their supervisor. Specifically, in both studies, we consistently found that the SCO of individual employees played a critical role in influencing the effect of LMX (dis)similarity. More precisely, in Study 1, LMX (dis)similarity had a significant effect on contempt and perceptions of received help only for the employees who had high levels of SCO; this was because those employees were more sensitive to social comparison information about their social standing. In addition, in Study 2, we directly measured the social comparison mechanisms underlying balance theory by asking the respondents to assess their own LMX in 
LMX dissimilarity and coworkers' interpersonal emotion

comparison to that of every other member of the work group. Again, the influence of perceived LMX (dis)similarity was more salient for employees with high rather than low SCO. In short, these results suggest that social comparison is the key mechanism driving the triadic balance underpinned by balance theory. Therefore, we suggest that future research should adopt the theoretical lens of social comparison to understand the intricacies of triadic relationships in relation to LMX.

Third, we make a unique theoretical contribution to the LMX differentiation literature. In practice, managers usually differentiate between their subordinates to some extent and tend to provide more support and resources for high LMX members with the expectation of high performance in return (Wayne, Shore, \& Liden, 1997; Li \& Qu, 2010). However, our research suggests that LMX dissimilarity may aggravate subordinates' performance. If managers form different relationship qualities (ranging from low to high) with different members, the objective performance of both low and high LMX members may suffer because the resulting interpersonal hostile feelings will undermine interactions between in- and out-group members. To the extent that LMX dissimilarity triggers dysfunctional emotions and interactions between coworkers, it will have a tangible negative impact on performance with the potential to inflict serious harm on organizations. By considering the relational and emotional impact of differential coworkers' LMX and the role of social comparison, our study offers new insights into the complexity and far-reaching consequences of LMX differentiation.

\section{Limitations and Future Research Directions}

This study has several limitations that should be addressed in future research. First, we used abbreviated scales to measure contempt and perceptions of help received from coworkers. Although these were examined in the pilot study, we acknowledge that the shortened scales may 
LMX dissimilarity and coworkers' interpersonal emotion

not be as reflective of their theoretical concepts as the original scales are, and thus inflated their measurement error for parameter estimation. Given that the round-robin research design is laborious and requires respondents to provide ratings for each of their coworkers, we followed previous research by using shortened scales to minimize participant fatigue (see de Jong et al., 2007; Lam et al., 2011; Venkataramani \& Dalal, 2007). Notably, our items were adapted from well-established scales that have reported strong reliability and validity (de Jong et al., 2007; Fiske et al., 2002). Overall, we believe that the use of abbreviated scales has not resulted in any measurement concern that would invalidate our findings. Nevertheless, future studies may find it fruitful to utilize full scales to measure all of the variables tested in this study.

Second, common method bias may have influenced our findings because we used selfreport measures. However, several strengths of our study (e.g., the objective measure of sales performance; independent ratings of LMX; discriminant validity shown in CFAs) may outweigh such a concern. Third, the interpretation of the causal relationship may be limited due to our cross-sectional design. Future studies could use a cross-lagged panel or experimental design and include multisource data.

Finally, our samples were drawn from two organizations in China, a country whose culture is known to be highly collectivistic (Hofstede, 2001). It is uncertain whether this might set a ceiling effect on the extent to which an employee would report his/her LMX with the supervisor and perceptions about his/her LMX compared with that of another coworker (i.e., LMXSC). This is possible because LMXSC in Study 2 and the interaction between coworker A's and coworker B's LMX in Study 1 were found to be unrelated to A's contempt for B. It may be of benefit to replicate the present investigation by including cultural values such as power 
LMX dissimilarity and coworkers' interpersonal emotion

distance or collectivism/individualism as team-level boundary conditions to examine whether or not the hypothesized relationships change in different cultural contexts.

Beyond addressing these limitations, future research could also expand the present model by considering other moderators. Besides the individual differences in SCO, other individual or contextual factors may regulate how employees respond to their coworkers' (dis)similar LMX, including personal factors such as neuroticism (Buunk et al., 2009), self-esteem (Aspinwall \& Taylor, 1993), and the need to belong (Baumeister \& Learly, 1995; Cornelis, Van Hiel, \& De Cremer, 2012), and contextual features such as the degree of task interdependence between team members (Duffy, Ganster, Shaw, Johnson, \& Pagon, 2006), teams' task and relationship conflict (De Dreu \& Weingart, 2003), justice climate (Erdogan \& Bauer, 2010), and LMX median (Liden, Erdogan, Wayne, \& Sparrowe, 2006).

Of particular interest are relational factors such as asymmetry in task dependence (de Jong et al., 2007) and expertise diversity (Van der Vegt et al., 2006) that convey a power difference between two individuals (Emerson, 1962). A balance theory viewpoint would suggest that coworkers in a triadic leader-member relationship would expect equal status (i.e., LMX similarity). Deviation from this setting would motivate employees to fight for a balance in LMX status by expressing contempt in order to maintain high status and avoid a drop of status. However, legitimate power differences between two coworkers may play a role in their reactions to LMX dissimilarity. For example, the low-power individual (e.g., low skill, less experiences) may see the LMX dissimilarity as normative and legitimate in the hierarchy, making him/her conform and submit (submission rather than contempt) to the coworker who has higher LMX (Keltner, Gruenfeld, \& Anderson, 2003). By considering the role of power-related factors, 
LMX dissimilarity and coworkers' interpersonal emotion

scholars can explore the differential effects of LMX dissimilarity on employees' emotional experiences.

Alternatively, future research could extend this study by considering a broader range of emotions. Balance theory suggests that while triadic imbalance causes negative interpersonal sentiments, triadic balance induces positive interpersonal emotions. We chose to focus only on the hostile emotion of contempt in the current study because the emotion literature suggests that negative emotions may have more powerful and lasting effects than positive ones (e.g., Basch \& Fisher, 2000; Baumeister, Bratslavsky, Finkenauer, \& Vohs, 2001). Moreover, employees tend to pay more attention to the antecedents of negative emotions and to be more responsive to them generally (Lian, Brown, Ferris, Liang, Keeping, Morrison, in press). Thus, future research may benefit from further examining how LMX (dis)similarity shapes different types of positive and negative interpersonal emotions, thereby addressing calls for greater consideration of discrete emotions in organizational research (Gooty, Gavin, \& Ashkanasy, 2009).

\section{Practical Implications}

This study has important implications for leadership and management in organizations.

Our results indicate that the relationship between LMX (dis)similarity and the emotional reactions between two coworkers hinges on employees' levels of SCO. Coworkers with high levels of SCO are more likely to feel contempt for each other because they are more sensitive to their relative standing in the context of (dis)similar LMX. Since contempt decreases coworkers' perceptions of receiving help from others and eventually affects performance, it is important to promote similar levels of LMX in a team setting. Although social comparisons among high SCO coworkers may be unavoidable in most work situations, managers could enhance the positive and curtail the negative implications associated with such social comparison processes by creating a 
LMX dissimilarity and coworkers' interpersonal emotion

fair team context and a positive affective climate (Tse et al., 2005; Tse, Dasborough, \& Ashkanasy 2008). Specifically, research argues that managers can reinforce the value of LMX by promoting a justice climate (Erdogan \& Bauer, 2010), demonstrating fair LMX differentiation criteria (e.g., performance standards rather than subjective preferences; Tse et al., 2005), and ensuring the criteria are consistent with the goals, demands, and norms of the work group, organization, and market (Henderson et al., 2008). These practices can increase employees' acceptance of differential LMX quality and help them better adjust the development of LMX based on the criteria. Alternatively, organizations may provide functional human resources initiatives to reduce employees' reliance on leaders to attain valued resources, thus giving the role of LMX differentiation less influence over subordinates (Henderson, Liden, Glibkowski, \& Chaudhry, 2009). By helping teams to manage LMX differentiation effectively, organizations may render LMX dissimilarity less likely, reducing its negative impact on coworkers' interpersonal emotions, interactions, and performance. 
LMX dissimilarity and coworkers' interpersonal emotion

\section{References}

Aiken, L. S., \& West, S. G. (1991). Multiple regression: Testing and interpreting interactions. Newbury Park, CA: Sage Publications.

Aron, A., Aron, E. N., Tudor, M., \& Nelson, G. (1991). Close relationships as including other in the self. Journal of Personality and Social Psychology, 60, 241-253.

Ashton-James., C. E., \& Ashkanasy, N. M. (2008). Affective events theory: A strategic perspective. In W. J. Zerbe, C. E. J. Hartel, \& N. M. Ashkanasy (Eds.), Research on emotion in organizations: Emotions, ethics, and decision-making (Vol. 4, pp. 1-59). London: Emerald.

Aspinwall, L. G., \& Taylor, S. E. (1993). Effects of social comparison direction, threat, and selfesteem on affect, self-evaluation, and expected success. Journal of Personality and Social Psychology, 64(5), 708-722.

Basch, J., \& Fisher, C. D. (2000). Affective events-emotions matrix: A classification of work events and associated emotions. In N. M. Ashkanasy, C. E. J. Härtel, \& W. J. Zerbe (Eds.), Emotions in the workplace: Research, theory and practice (pp. 36-48). London: Quorum Books.

Baumeister, R. F., Bratslavsky, E., Finkenauer, C., \& Vohs, K. D. (2001). Bad is stronger than good. Review of General Psychology, 5, 323-370.

Baumeister, R. F., \& Leary, M. R. (1995). The need to belong: Desire for interpersonal attachments as a fundamental human motivation. Psychological Bulletin, 117, 497-529.

Bliese, P. D. (2000). Within-group agreement, non-independence, and reliability: Implications for data aggregation and analysis. In K. J. Klein \& S. W. J. Kozlowski (Eds.), Multilevel theory, research, and methods in organizations (pp. 349-381). San Francisco, CA: Jossey-Bass. 
LMX dissimilarity and coworkers' interpersonal emotion

Brislin, R., Lonner, W. J., \& Thorndike, R. (1973). Cross-cultural research methods. New York: Wiley.

Buunk, A. P., Brakel, T. M., Bennenbroek, F. T. C., Stiegelis, H. E., Sanderman, R., van den Bergh, A. C. M...Hagedoorn, M. (2009). Neuroticism and responses to social comparison among cancer patients. European Journal of Personality, 23, 475-487.

Buunk, A. P., \& Gibbons, F. X. (2007). Social comparison: The end of a theory and the emergence of a field. Organizational Behavior and Human Decision Processes, 102, 321.

Buunk, A. P., \& Mussweiler, T. (2001). New directions in social comparison research. European Journal of Social Psychology, 31, 467-475.

Buunk, B. P., Zurriaga, R., Peiro, J. M., Nauta, A., \& Gosalvez, I. (2005). Social comparisons at work as related to a cooperative social climate and to individual differences in social comparison orientation. Applied Psychology, 54, 61-80.

Byrne, D. (1971). The attraction paradigm. New York: Academic Press.

Cornelis, I., Van Hiel, A., \& De Cremer, D. (2012). The effect of followers' belongingness needs on leaders' procedural fairness enactment mediation through interpersonal and team attraction. Journal of Personnel Psychology, 11(1), 31-39.

Cuddy, A. J. C., Fiske, S. T., \& Glick, P. (2007). The BIAS map: Behaviors from intergroup affect and stereotypes. Journal of Personality and Social Psychology, 92, 631-648.

Dansereau, F., Graen, G. B., \& Haga, W. J. (1975). A vertical dyad linkage approach to leadership within formal organizations. Organizational Behavior and Human Performance, 13, 46-78. 
LMX dissimilarity and coworkers' interpersonal emotion

De Dreu, C. K. W., \& Weingart, L. R. (2003). Task versus relationship conflict, team performance, and team member satisfaction: A meta-analysis. Journal of Applied Psychology, 88, 741-749.

de Jong, S. B., Van der Vegt, G. S., \& Molleman, E. (2007). The relationships among asymmetry in task dependence, perceived helping behavior, and trust. Journal of Applied Psychology, 92, 1625-1637.

Dirks, K. T. (1999). The effects of interpersonal trust on work group performance. Journal of Applied Psychology, 84, 445-455.

Duchon, D., Green, S. G., \& Taber, T. D. (1986). Vertical dyad linkage: A longitudinal assessment of antecedents, measures, and consequences. Journal of Applied Psychology, $71,56-60$.

Duffy, M. K., Ganster, D. C., Shaw, J. D., Johnson, J. L., \& Pagon, M. (2006). The social context of undermining behavior at work. Organizational Behavior and Human Decision Processes, 101, 105-126.

Edwards, J. R. (1994). The study of congruence in organizational behavior research: Critique and a proposed alternative. Organizational Behavior and Human Decision Processes, 58, 51100.

Edwards, J. R. (2001). Ten difference score myths. Organizational Research Methods, 3, 265287.

Ekman, P. (1994). The nature of emotion: Fundamental questions. New York: Oxford University Press.

Elfenbein, H. A. (2007). Emotion in organization: A review and theoretical integration. Academy of Management Annals, 1, 315-386. 
LMX dissimilarity and coworkers' interpersonal emotion

Emerson, R. M. (1962). Power-dependence relations. American Sociological Review, 27, 31-41.

Erdogan, B., \& Bauer, T. N. (2010). Differentiated leader-member exchanges: The buffering role of justice climate. Journal of Applied Psychology, 95, 1104-1120.

Festinger, L. (1954). A theory of social comparison processes. Human Relations, 7, 117-140.

Fischer, A. H., \& Roseman, I. J. (2007). Beat them or ban them: The characteristics and social functions of anger and contempt. Journal of Personality and Social Psychology, 93, 103115.

Fiske, S. T., Cuddy, A. J. C., Glick, P., \& Xu, J. (2002). A model of (often mixed) stereotype content: Competence and warmth respectively follow from perceived status and competition. Journal of Personality and Social Psychology, 82, 878-902.

Forgas, J. P. (2002). Feeling and doing: Affective influences on interpersonal behavior. Psychological Inquiry, 13, 1-28.

Forgas, J. P., \& Smith, C. A. (2003). Affect and emotion. In M. A. Hogg \& J. Cooper (Eds.), The Sage handbook of social psychology (pp. 161-189). Thousand Oaks, CA: Sage.

Freeman, L. C., Freeman, S. C., \& Michaelson, A. G. (1988). On human intelligence. Journal of Social and Biological Structures, 11, 415-425.

Gerstner, C. R., \& Day, D. V. (1997). Meta-analytic review of leader-member exchange theory: Correlates and construct issues. Journal of Applied Psychology, 82, 827-844.

Gibbons, F. X., \& Buunk, B. P. (1999). Individual differences in social comparison: Development of a scale of social comparison orientation. Journal of Personality and Social Psychology, 76, 129-142.

Gooty, J., Gavin, M., \& Ashkanasy, N. M. (2009). Emotion research in OB: The challenges that lie ahead. Journal of Organizational Behavior, 30, 833-838. 
LMX dissimilarity and coworkers' interpersonal emotion

Graen, G. B., \& Uhl-Bien, M. (1995). Relationship-based approach to leadership: Development of leader-member exchange (LMX) theory of leadership over 25 years: Applying a multilevel multi-domain perspective. Leadership Quarterly, 6, 219-247.

Greenberg, J., Ashton-James, C.E., \& Ashkanasy, N. M. (2007). Social comparison processes in organizations. Organizational Behavior and Human Decision Processes, 102, 22-41.

Halbesleben, J. R. B. (2006). Sources of social support and burnout: A meta-analytic test of the conservation of resources model. Journal of Applied Psychology, 91, 1134-1145.

Heider, F. (1944). Social perception and phenomenal causality. Psychological Review, 51, 358374.

Heider, F. (1946). Attitudes and cognitive organization. Journal of Psychology, 21, 107-112.

Heider, F. (1958). The psychology of interpersonal relations. Hillsdale, NJ: Lawrence Erlbaum Associates.

Henderson, D. J., Liden, R. C., Glibkowski, B. C., \& Chaudhry, A. (2009). LMX differentiation: A multilevel review and examination of its antecedents and outcomes. Leadership Quarterly, 20, 517-534.

Henderson, D. J., Wayne, S. J., Shore, L. M., Bommer, W. H., \& Tetrick, L. E. (2008). Leadermember exchange, differentiation, and psychological contract fulfillment: A multilevel examination. Journal of Applied Psychology, 93, 1208-1219.

Hess, U. (2009). Contempt. In D. Sander \& K. R. Scherer (Eds.), Oxford companion to emotion and the affective sciences (pp. 99-100). Oxford, UK: Oxford University Press.

Hofstede, G. (2001). Culture's consequences: Comparing values, behaviors, institutions, and organizations across nations (2nd ed.). Thousand Oaks, CA: Sage Publications. 
LMX dissimilarity and coworkers' interpersonal emotion

Hogg, M. A. (2000). Social identity and social comparison. In J. Suls \& L. Wheeler (Eds.), Handbook of social comparison: Theory and research (pp. 401-422). New York: Plenum.

Huang, X., \& Iun, J. (2006). The impact of subordinate-supervisor similarity in growth-need strength on work outcomes: The mediating role of perceived similarity. Journal of Organizational Behavior, 27, 1121-1148.

Hutcherson, C. A., \& Gross, J. J. (2011). The moral emotions: A social-functionalist account of anger, disgust, and contempt. Journal of Personality \& Social Psychology, 100, 719-737.

Ilies, R., Nahrgang, J. D., \& Morgeson, F. P. (2007). Leader-member exchange and citizenship behaviors: A meta-analysis. Journal of Applied Psychology, 92, 269-277.

James, L. R., Demaree, R. G., \& Wolf, G. (1984). Estimating within-group inter-rater reliability with and without response bias. Journal of Applied Psychology, 69, 86-98.

Keltner, D., \& Haidt, J. (1999). Social functions of emotions at four levels of analysis. Cognition \& Emotion, 13, 505-521.

Keltner, D., Gruenfeld, D. H., \& Anderson, C. (2003). Power, approach, and inhibition. Psychological Review, 110, 265-284.

Kenny, D. A. (1994). Interpersonal perception: A social relations analysis. New York: Guilford Press.

Kenny, D. A., Kashy, D. A., \& Cook, W. L. (2006). Dyadic data analysis. New York: Guilford Press.

Kenny, D. A., \& La Voie, L. (1984). The social relations model. In L. Berkowitz (Ed.), Advances in experimental social psychology (pp. 142-182). Orlando, FL: Academic Press.

Krosnick, J. A., Betz, A. L., Jussim, L. J., \& Lynn, A. R. (1992). Subliminal conditioning of attitudes. Personality and Social Psychology Bulletin, 18, 152-162. 
LMX dissimilarity and coworkers' interpersonal emotion

Krull, J. L., \& MacKinnon, D. P. (2001). Multilevel modeling of individual and group level mediated effects. Multivariate Behavioural Research, 36, 249-277.

Lam, C. K., Van der Vegt, G. S., Walter, F., \& Huang, X. (2011). Harming high performers: A social comparison perspective on interpersonal harming in work teams. Journal of Applied Psychology, 96, 588-601.

Lee, R. T., \& Ashforth, B. E. (1996). A meta-analytic examination of the correlates of the three dimensions of job burnout. Journal of Applied Psychology, 81, 123-133.

Li, M., \& Qu, Q. (2010). Differentiation in leader-member exchange: A hierarchical linear modelling approach. Leadership Quarterly, 21, 733-744.

Lian, H., Brown, D. J., Ferris, D. L., Liang, L. H., Keeping, L. M., \& Morrison, R. (in press). Abusive supervision and retaliation: A self-control framework. Academy of Management Journal. doi:10.5465/amj.2011.0977

Liden, R. C., Erdogan, B., Wayne, S. J., \& Sparrowe, R. T. (2006). Leader-member exchange, differentiation, and task interdependence: Implications for individual and group performance. Journal of Organizational Behavior, 27, 723-746.

Lyons, B. J., \& Scott, B. A. (2012). Integrating social exchange and affective explanations for the receipt of help and harm: A social network approach. Organizational Behavior and Human Decision Processes, 117, 66-79.

MacKinnon, D. P., Lockwood, C. M., \& Williams, J. (2004). Confidence limits for the indirect effect: Distribution of the product and resampling methods. Multivariate Behavioral Research, 39, 99-128. 
LMX dissimilarity and coworkers' interpersonal emotion

Melwani, S., \& Barsade, S. G. (2011). Held in contempt: The psychological, interpersonal, and performance consequences of contempt in a work context. Journal of Personality and Social Psychology, 101, 503-520.

Neuberg, S. L., \& Cottrell, C. A. (2002). Intergroup emotions: A sociofunctional approach. In D. M. Mackie \& E. R. Smith (Eds.), From prejudice to intergroup emotions: Differentiated reactions to social groups (pp. 265-283). New York; Hove: Psychology Press.

Petty, R. E. (1995). Attitude change. In A. Tesser (Ed.), Advanced social psychology (pp. 195255). New York: McGraw-Hill.

Reis, H. T., \& Collins, N. (2000). Measuring relationship properties and interactions relevant to social support. In S. Cohen, L. G. Underwood, \& B. H. Gottlieb (Eds.), Social support measurement and intervention: A guide for health and social scientists (pp. 136-192). London: Oxford University Press.

Richter, A. W., West, M. A., van Dick, R., \& Dawson, J. F. (2006). Boundary spanners' identification, intergroup contact, and effective intergroup relations. Academy of Management Journal, 49, 1252-1269.

Rockstuhl, T., Dulebohn, J. H., Ang, S., \& Shore, L. M. (2012). Leader-member exchange (LMX) and culture: A meta-analysis of correlates of LMX across 23 countries. Journal of Applied Psychology, 97, 1097-1130.

Roseman, I. J. (2001). A model of appraisal in the emotion system: Integrating theory, research, and applications. In K. R. Scherer, A. Schorr, \& T. Johnstone (Eds.), Appraisal processes in emotion: Theory, methods, research (pp. 68-91). New York: Oxford University Press.

Rozin, P., Lowery, L., Imada, S., \& Haidt, J. (1999). The CAD triad hypothesis: A mapping between three moral emotions (contempt, anger, disgust) and three moral codes 
LMX dissimilarity and coworkers' interpersonal emotion

(community, autonomy, divinity). Journal of Personality and Social Psychology, 76, 574586.

Scandura, T. A., \& Graen, G. B. (1984). Moderating effects of initial leader member exchange status on the effects of a leadership intervention. Journal of Applied Psychology, 69, 428436.

Schriesheim, C. A., Castro, S. L., Zhou, X., \& Yammarino, F. J. (2001). The folly of theorizing "A" but testing "B": A selective level-of-analysis review of the field and a detailed leader-member exchange illustration. Leadership Quarterly, 12, 515-551.

Schwarz, N., \& Clore, G. L. (1996). Feelings and phenomenal experiences. In E. T. Higgins \& A. W. Kruglanski (Eds.), Social psychology: Handbook of basic principles (pp. 433-465). New York: Guilford Press.

Selig, J. P., \& Preacher, K. J. (2008). Monte Carlo method for assessing mediation: An interactive tool for creating confidence intervals for indirect effects [Computer software]. Retrieved from http://www.quantpsy.org.

Settoon, R. P., \& Mossholder, K. W. (2002). Relationship quality and relationship context as antecedents of person-and task-focused interpersonal citizenship behavior. Journal of Applied Psychology, 87, 255-267.

Shah, J. (2003). Automatic for the people: How representations of significant others implicitly affect goal pursuit. Journal of Personality and Social Psychology, 84, 661-681.

Sherony, K. M., \& Green, S. G. (2002). Co-worker exchange: Relationships between coworkers, leader-member exchange, and work attitudes. Journal of Applied Psychology, $87,542-548$. 
LMX dissimilarity and coworkers' interpersonal emotion

Silvester, J. (1997). Spoken attributions and candidate success in graduate recruitment interviews. Journal of Personality and Social Psychology, 52, 1061-1086.

Snijders, T. A. B., \& Kenny, D. A. (1999). The social relations model for family data: A multilevel approach. Personal Relationships, 64, 471-486.

Sobel, M. E. (1982). Asymptotic confidence intervals for indirect effects in structural equation models. In S. Leinhardt (Ed.), Sociological methodology (pp. 290-312). Washington, DC: American Sociological Association.

Sparrowe, R. T., \& Liden, R. C. (1997). Process and structure in leader-member exchange. Academy of Management Review, 22, 522-552.

Spence, J. R., Ferris, D. L., Brown, D. J., \& Heller, D. (2011). Understanding daily citizenship behavior. A social comparison perspective. Journal of Organizational Behavior, 32, 547571.

Stratton, M. T. (2005). An affective events theory-based conceptual model of emotional ambivalence in the context of personal web-usage monitoring. In N. M. Ashkanasy, W. J. Zerbe, \& C. E. J. Hartel (Eds.), Research on emotion in organizations: The effect of affect in organizational settings (Vol. 1, pp. 47-76). Amsterdam, the Netherlands: Elsevier.

Tse, H. M., Ashkanasy, N. M., \& Dasborough, M. (2012). Relative leader-member exchange, negativity and social identification: A moderated-mediation examination. Leadership Quarterly, 23, 354-366.

Tse, H. M., Dasborough, M. T., \& Ashkanasy, N. M. (2005). The role of affect, fairness and social perception in team member exchange. In N. M. Ashkanasy, C. E. J Härtel, \& W. J. Zerbe (Eds.), Research on emotion in organizations: The effect of affect in organizational settings (pp. 43-171). Oxford, UK: Elsevier Science. 
LMX dissimilarity and coworkers' interpersonal emotion

Tse, H. M., Dasborough, M. T., \& Ashkanasy, N. M. (2008). A multi-level analysis of team climate and interpersonal exchange relationships at work. Leadership Quarterly, 19, 195211.

Van der Vegt, G. S., Bunderson, J. S., \& Oosethof, A. (2006). Expertness diversity and interpersonal helping in teams: Why those who need the most help end up getting the least. Academy of Management Journal, 49, 877-893.

Venkataramani, V., \& Dalal, R. S. (2007). Who helps and harms whom? Relational antecedents of interpersonal helping and harming in organizations. Journal of Applied Psychology, 92, 952-966.

Venkataramani, V., Green, S. D., \& Schleicher, D. J. (2010). Well-connected leaders: The impact of leaders' social network ties on LMX and members' work attitudes. Journal of Applied Psychology, 95, 1071-1084.

Vidyarthi, P. R., Liden, R. C., Anand, S., Erdogan, B., \& Ghosh, S. (2010). Where do I stand? Examining the effects of leader-member exchange social comparison on employee work behaviors. Journal of Applied Psychology, 98, 849-861.

Warner, R. M., Kenny, D. A., \& Stoto, M. (1979). A new round robin analysis of variance for social interaction data. Journal of Personality and Social Psychology, 37, 1742-1757.

Watson, D., Clark, L. A., \& Tellegen, A. (1988). Development and validation of brief measures of positive and negative affect: The PANAS scale. Journal of Personality and Social Psychology, 54, 1063-1070.

Wayne, S. J., Shore, L. M., \& Liden, R. C. (1997). Perceived organizational support and leadermember exchange: A social exchange perspective. Academy of Management Journal, 40, $82-111$. 
LMX dissimilarity and coworkers' interpersonal emotion

Weiss, H. M., \& Cropanzano, R. (1996). An affective events approach to job satisfaction. In B. M. Staw \& L. L. Cummings (Eds.), Research in organizational behavior (Vol. 18, pp. 174). Greenwich, CT: JAI Press.

Wood, J. V. (1996). What is social comparison and how should we study it? Personality and Social Psychology Bulletin, 22, 520-537. 
Table 1

Means, Standard Deviations, Intercorrelations, and Reliabilities of Study Variables (Study 1)

\begin{tabular}{|c|c|c|c|c|c|c|c|c|c|c|c|c|c|c|}
\hline Variables & $M$ & $S D$ & 1 & 2 & 3 & 4 & 5 & 6 & 7 & 8 & 9 & 10 & 11 & 12 \\
\hline 1. Gender & .44 & .50 & - & & & & & & & & & & & \\
\hline 2. Age & 25.24 & 5.15 & -.09 & - & & & & & & & & & & \\
\hline 3. Positive affectivity & 3.02 & .75 & $-.14 * *$ & $.19^{* *}$ & $(.75)$ & & & & & & & & & \\
\hline 4. Negative affectivity & 2.36 & .73 & .05 & -.02 & .07 & $(.70)$ & & & & & & & & \\
\hline 5. Dyadic tenure & 5.07 & 8.24 & -.01 & $.16^{* *}$ & .07 & .09 & - & & & & & & & \\
\hline 6. Team size & 7.82 & 5.42 & -.04 & $-.11 *$ & $-.22 * *$ & $.11^{*}$ & $.16^{* *}$ & - & & & & & & \\
\hline 7. Coworker A's LMX & 3.41 & .97 & $-.15 * *$ & -.09 & $.34 * *$ & $-.12^{*}$ & .06 & -.08 & $(.74)$ & & & & & \\
\hline 8. Coworker B's LMX & 3.41 & .97 & -.04 & .08 & .07 & .01 & .07 & .08 & -.03 & $(.74)$ & & & & \\
\hline 9. $\mathrm{SCO}$ & 3.50 & .76 & $-.10^{*}$ & -.00 & $.14 * *$ & $.20^{* *}$ & .06 & .07 & -.04 & .03 & (.64) & & & \\
\hline 10. Contempt & 1.37 & .66 & .02 & .06 & -.01 & $.24 * *$ & $.11^{*}$ & .06 & -.05 & .04 & -.02 & $(.87)$ & & \\
\hline $\begin{array}{l}\text { 11. A's perception of received help } \\
\text { from B }\end{array}$ & 3.08 & .87 & $-.11 *$ & .04 & $.18^{* * *}$ & $-.11 *$ & $.13^{* *}$ & -.03 & $.27 * *$ & -.04 & .07 & $-.25 * *$ & $(.94)$ & \\
\hline 12. Sales performance & 34.72 & 22.7 & $.11^{*}$ & .04 & $.11^{*}$ & -.04 & $.20^{* *}$ & $-.10^{*}$ & .10 & $.11^{*}$ & .06 & $-.17 * *$ & $.13 * *$ & - \\
\hline
\end{tabular}

Note. $\mathrm{LMX}=$ leader-member exchange; $\mathrm{SCO}=$ social comparison orientation. ${ }^{*} p<.05,{ }^{* *} p<.01$ 
LMX dissimilarity and coworkers' interpersonal emotion

Table 2

Variance Partitioning for Coworker A's Contempt for Coworker B and A's Perception of Received Help From B (Study 1)

\begin{tabular}{|c|c|c|c|c|}
\hline \multirow[b]{2}{*}{ Source of Variance } & \multicolumn{2}{|c|}{ Contempt } & \multicolumn{2}{|c|}{$\begin{array}{l}\text { A's perception of received help } \\
\text { from } B\end{array}$} \\
\hline & $B$ & $S E$ & $\boldsymbol{B}$ & $S E$ \\
\hline Group variance & $\begin{array}{c}.03 \\
(7 \%)\end{array}$ & .03 & $\begin{array}{c}.07 \\
(9 \%)\end{array}$ & .03 \\
\hline Actor variance & $\begin{array}{c}.11 \\
(26 \%)\end{array}$ & .03 & $\begin{array}{c}.20 \\
(26 \%)\end{array}$ & .03 \\
\hline Partner variance & $\begin{array}{c}.03 \\
(6 \%)\end{array}$ & .02 & $\begin{array}{c}.02 \\
(3 \%)\end{array}$ & .02 \\
\hline Dyadic variance & $\begin{array}{c}.26 \\
(61 \%)\end{array}$ & .03 & $\begin{array}{c}.47 \\
(62 \%)\end{array}$ & .03 \\
\hline Deviance & & & & \\
\hline
\end{tabular}

Note. $N=128$ individuals in 408 dyads within 31 teams 
LMX dissimilarity and coworkers' interpersonal emotion

Table 3

Social Relations Model Analyses for Coworker A's Contempt for Coworker B (Study 1)

\begin{tabular}{|c|c|c|c|c|c|c|}
\hline \multirow[b]{3}{*}{ Steps and Variables } & \multicolumn{6}{|c|}{ Contempt } \\
\hline & \multicolumn{2}{|c|}{ Model 1} & \multicolumn{2}{|c|}{ Model 2} & \multicolumn{2}{|c|}{ Model 3} \\
\hline & $B$ & $S E$ & $B$ & $S E$ & $B$ & $S E$ \\
\hline \multicolumn{7}{|l|}{ Control variables } \\
\hline A's Gender & -.05 & .08 & -.04 & .08 & -.03 & .09 \\
\hline A's Age & .01 & .01 & .01 & .01 & .01 & .01 \\
\hline Positive affectivity & -.05 & .06 & -.05 & .06 & -.05 & .06 \\
\hline Negative affectivity & $.18^{* *}$ & .06 & $.18^{* *}$ & .06 & $.17 * *$ & .06 \\
\hline B's Gender & $-.15 * *$ & .06 & $-.15 * *$ & .06 & $-.15^{*}$ & .06 \\
\hline B's Age & .00 & .01 & .00 & .01 & .00 & .01 \\
\hline Dyadic tenure & .01 & .00 & .01 & .00 & .01 & .00 \\
\hline Team size & .02 & .01 & .01 & .01 & .01 & .01 \\
\hline \multicolumn{7}{|l|}{ Main effects } \\
\hline A's LMX & .00 & .05 & -.01 & .05 & .00 & .05 \\
\hline B's LMX & .01 & .03 & -.01 & .03 & -.01 & .03 \\
\hline $\mathrm{SCO}$ & -.03 & .04 & -.03 & .04 & -.03 & .04 \\
\hline$\Delta \chi^{2}(11)$ & \multicolumn{2}{|c|}{26.70} & & & & \\
\hline
\end{tabular}

Two-way interaction

\begin{tabular}{lrrrr} 
A's LMX x B's LMX & -.03 & .03 & -.02 & .03 \\
A's LMX x SCO & .03 & .05 & .03 & .05 \\
B's LMX x SCO & .05 & .03 & .04 & .03 \\
$\Delta \chi^{2}(3)$ & \multicolumn{3}{c}{5.10} &
\end{tabular}

Three-way interaction
A's LMX x B's LMX x SCO
$-.08 * * \quad .03$
$\Delta \chi^{2}(1)$
$6.95 * *$

Note. $N=408$ dyads. $\mathrm{LMX}=$ leader-member exchange; $\mathrm{SCO}=$ social comparison orientation. ${ }^{*} p<.05,{ }^{* *} p<.01$ 
LMX dissimilarity and coworkers' interpersonal emotion

Table 4

Social Relations Model Analyses for Coworker A's Perception of Received Help from Coworker $B$ and Conditional Indirect Relationships (Study 1)

\begin{tabular}{|c|c|c|}
\hline \multirow[b]{2}{*}{ Steps and variables } & \multicolumn{2}{|c|}{ A's perception of received help from $B$} \\
\hline & $\boldsymbol{B}$ & $S E$ \\
\hline \multicolumn{3}{|l|}{ Step 1} \\
\hline A's Gender & -.05 & .11 \\
\hline A's Age & .03 & .01 \\
\hline Positive affectivity & .14 & .08 \\
\hline Negative affectivity & -.09 & .07 \\
\hline B's Gender & .13 & .08 \\
\hline B's Age & .01 & .01 \\
\hline Dyadic tenure & .01 & .01 \\
\hline Team size & -.01 & .01 \\
\hline A's LMX & $.19 * *$ & .06 \\
\hline B's LMX & -.05 & .04 \\
\hline $\mathrm{SCO}$ & .05 & .05 \\
\hline$\Delta \chi^{2}(11)$ & \multicolumn{2}{|c|}{$41.1 * *$} \\
\hline \multicolumn{3}{|l|}{ Step 2} \\
\hline A's LMX x B's LMX & .05 & .05 \\
\hline A's LMX x SCO & -.07 & .06 \\
\hline B's LMX x SCO & -.01 & .03 \\
\hline$\Delta \chi^{2}(3)$ & \multicolumn{2}{|c|}{2.28} \\
\hline \multicolumn{3}{|l|}{ Step 3} \\
\hline A's LMX x B's LMX x SCO & $.09 * *$ & .03 \\
\hline$\Delta \chi^{2}(1)$ & \multicolumn{2}{|c|}{$7.07 * *$} \\
\hline \multicolumn{3}{|l|}{ Step 4} \\
\hline A's contempt for B & $-.24 * *$ & .06 \\
\hline$\Delta \chi^{2}(1)$ & \multicolumn{2}{|c|}{$35.42 * *$} \\
\hline
\end{tabular}

Conditional indirect relationship between Coworker B's LMX and Coworker A's Perception of Received Help from Coworker B, through A's Contempt for B ${ }^{\text {a }}$

\begin{tabular}{|c|c|c|c|c|}
\hline \multicolumn{2}{|c|}{ Moderators } & \multicolumn{3}{|c|}{ A's perception of received help from $B$} \\
\hline SCO & A's LMX & $\begin{array}{c}\text { Indirect } \\
\text { effect }\end{array}$ & Sobel Z & 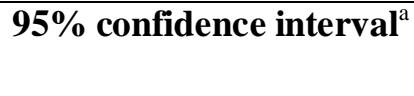 \\
\hline High (+1SD) & High (+1SD) & .04 & $1.90^{*}$ & $.01, .08$ \\
\hline $\operatorname{High}(+1 \mathrm{SD})$ & Low (-1SD) & -.04 & $-1.94 *$ & $-.08,-.01$ \\
\hline Low (-1SD) & High (+1SD) & .00 & .00 & $-.04, .04$ \\
\hline Low (-1SD) & Low (-1SD) & .02 & .98 & $-.01, .06$ \\
\hline
\end{tabular}

Note. $N=408$ dyads. $\mathrm{LMX}=$ leader-member exchange; $\mathrm{SCO}=$ social comparison orientation.

${ }^{a}$ Based on 20,000 Monte Carlo samples (Selig \& Preacher, 2008). $-1 S D=$ one standard deviation below the mean. $+1 S D=$ one standard deviation above the mean. ${ }^{*} p<.05,{ }^{* *} p<.01$ 
Table 5

Means, Standard Deviations, Intercorrelations, and Reliabilities of Study Variables (Study 2)

\begin{tabular}{|c|c|c|c|c|c|c|c|c|c|c|c|}
\hline Variables & $M$ & $S D$ & 1 & 2 & 3 & 4 & 5 & 6 & 7 & 8 & 9 \\
\hline 1. Gender & .29 & .46 & - & & & & & & & & \\
\hline 2. Age & 25.56 & 3.07 & -.09 & - & & & & & & & \\
\hline 3. Positive affectivity & 3.35 & .63 & .03 & .04 & $(.80)$ & & & & & & \\
\hline 4. Negative affectivity & 2.75 & .64 & $-.14 *$ & -.08 & .09 & $(.76)$ & & & & & \\
\hline 5. Dyadic tenure & 7.74 & 4.21 & $-.12 *$ & .09 & .00 & $.29 * *$ & - & & & & \\
\hline 6. Team size & 5.41 & 1.50 & .09 & $-.36 * *$ & .10 & -.11 & $-.23^{* *}$ & - & & & \\
\hline 7. Coworker A's LMXSC & 2.75 & .94 & $-.23 * *$ & $-.16^{* *}$ & $.18^{* *}$ & $.15^{*}$ & .04 & .07 & $(.95)$ & & \\
\hline 8. $\mathrm{SCO}$ & 3.43 & .52 & .03 & -.04 & $.27 * *$ & $.21 * *$ & .05 & .08 & .08 & $(.73)$ & \\
\hline 9. Contempt & 1.36 & .80 & $-.17 * *$ & -.05 & $.19 * *$ & $.54 * *$ & $.25^{* *}$ & .07 & $.33 * *$ & $.24 * *$ & $(.97)$ \\
\hline
\end{tabular}

Note. LMXSC = LMX social comparison; $\mathrm{SCO}=$ social comparison orientation.

${ }^{*} p<.05, \stackrel{* *}{p}<.01$ 
LMX dissimilarity and coworkers' interpersonal emotion

Table 6

Variance Partitioning for Coworker A's Contempt for Coworker B (Study 2)

\begin{tabular}{lcc}
\hline & \multicolumn{2}{c}{ Contempt } \\
\hline \multicolumn{1}{c}{ Source of Variance } & $\boldsymbol{B}$ & $\boldsymbol{S E}$ \\
\hline \multirow{2}{*}{ Group variance } & .00 & .00 \\
& $(0 \%)$ & \\
Actor variance & .56 & .01 \\
& $(74 \%)$ & \\
Partner variance & .01 & .01 \\
& $(2 \%)$ & \\
Dyadic variance & .18 & .00
\end{tabular}

Deviance

1234.90

Note. $N=68$ individuals in 260 dyads within 17 teams 
LMX dissimilarity and coworkers' interpersonal emotion

Table 7

Social Relations Model Analyses for Coworker A's Contempt for Coworker B (Study 2)

\begin{tabular}{|c|c|c|c|c|c|c|}
\hline \multirow[b]{3}{*}{ Steps and Variables } & \multicolumn{6}{|c|}{ Contempt } \\
\hline & \multicolumn{2}{|c|}{ Model 1} & \multicolumn{2}{|c|}{ Model 2} & \multicolumn{2}{|c|}{ Model 3} \\
\hline & $B$ & $S E$ & $B$ & $S E$ & $B$ & $S E$ \\
\hline \multicolumn{7}{|l|}{ Control variables } \\
\hline A's Gender & -.17 & .16 & -.16 & .16 & -.15 & .15 \\
\hline A's Age & .00 & .02 & .00 & .02 & .00 & .02 \\
\hline Positive affectivity & .07 & .12 & .07 & .12 & .07 & .11 \\
\hline Negative affectivity & $.51^{* *}$ & .12 & $.50 * *$ & .12 & $.50 * *$ & .12 \\
\hline B's Gender & .03 & .07 & .03 & .07 & .03 & .07 \\
\hline B's Age & .02 & .01 & .02 & .01 & .02 & .01 \\
\hline Dyadic tenure & $.02 *$ & .01 & .02 & .01 & .02 & .01 \\
\hline Team size & .06 & .05 & .06 & .05 & .06 & .05 \\
\hline \multicolumn{7}{|l|}{ Main effects } \\
\hline A's LMXSC & .09 & .05 & .09 & .06 & .11 & .06 \\
\hline $\mathrm{A}^{\prime} \mathrm{s} \mathrm{LMXSC}^{2}$ & .00 & .04 & .00 & .04 & .02 & .04 \\
\hline $\mathrm{SCO}$ & .07 & .07 & .07 & .07 & .02 & .07 \\
\hline$\Delta \chi^{2}(11)$ & \multicolumn{2}{|c|}{$915.51 * *$} & & & & \\
\hline
\end{tabular}

Two-way interaction

$\begin{array}{lllllll}\text { A's LMXSC x SCO } & .02 & & .05 & & .07 & .06 \\ \Delta \chi^{2}(1) & & & .09 & & & \end{array}$

Quadratic interaction term
$\mathrm{A}^{\prime} \mathrm{s} \mathrm{LMXSC}^{2} \mathrm{x} \mathrm{SCO}$
$.08 * \quad .04$
$\Delta \chi^{2}(1)$
$4.89 *$

Note. $N=260$ dyads. LMXSC $=$ LMX social comparison; $\mathrm{SCO}=$ social comparison orientation .

${ }^{*} p<.05,{ }^{* *} p<.01$ 
Table 8

Tests of Simple Slopes (Study 2)

\begin{tabular}{llcc}
\hline Moderator value & Predictor value & \multicolumn{2}{c}{ Contempt } \\
\cline { 3 - 4 } SCO & LMXSC & $\boldsymbol{B}$ & S.E. \\
\hline High & Low & $-.29^{*}$ & .13 \\
High & Medium & .06 & .06 \\
High & High & $.37^{*}$ & .17 \\
Low & Low & .16 & .09 \\
Low & Medium & .04 & .06 \\
Low & High & -.09 & .13 \\
\hline
\end{tabular}

Note. $\mathrm{LMXSC}=\mathrm{LMX}$ social comparison; $\mathrm{SCO}=$ social comparison orientation. High $=$ one

standard deviation above the mean. Medium $=$ mean value. Low $=$ one standard deviation below the mean.

$\stackrel{*}{p}<.05$ 
Individual Level

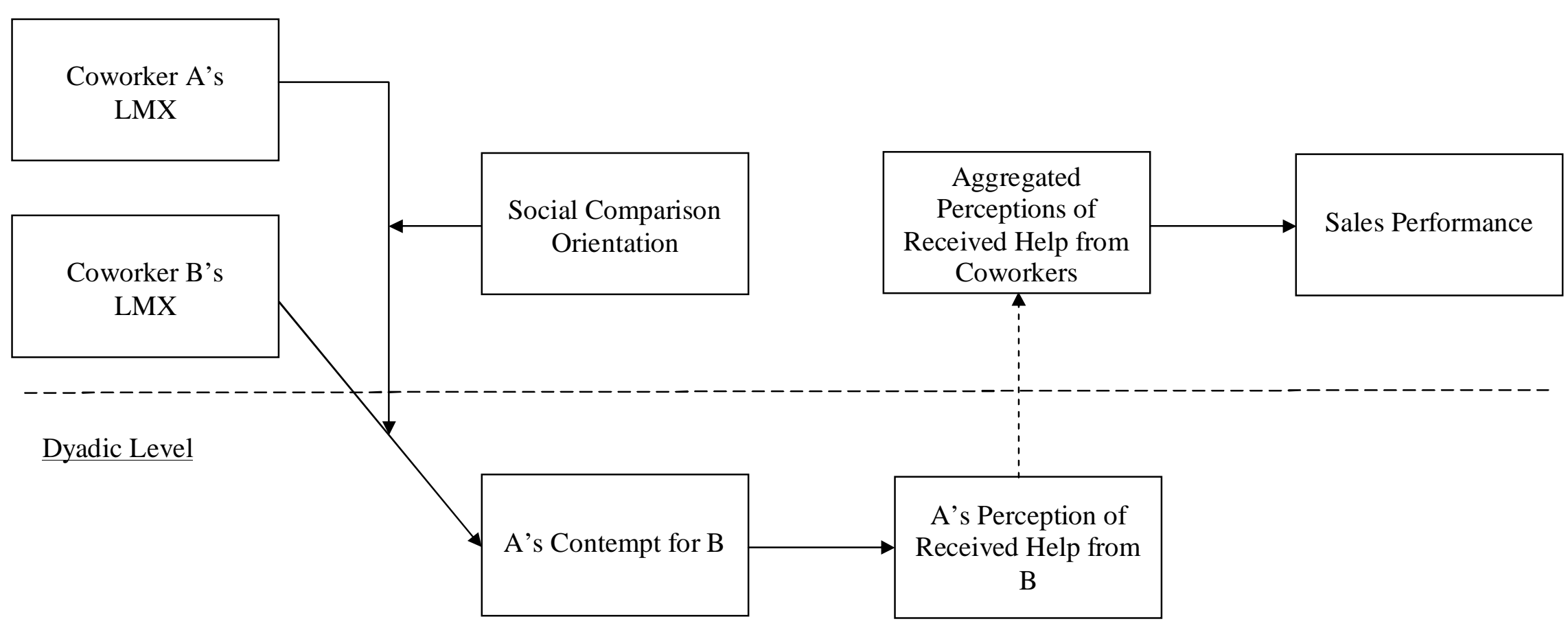

Figure 1. Hypothesized model linking coworkers' LMX, contempt, and perceptions of received help in coworker dyads. The dashed arrow reflects an aggregation mechanism. LMX = leader-member exchange. 


\section{High SCO}

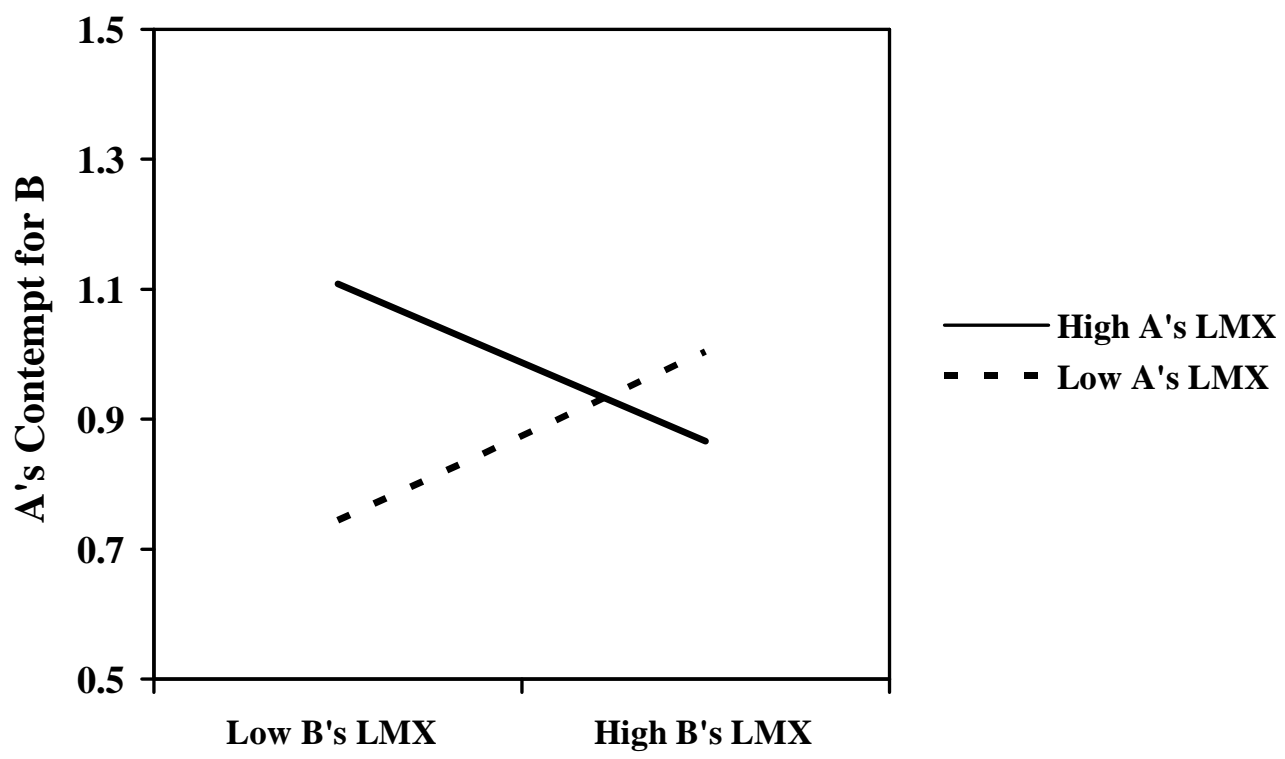

$2 b$

\section{Low SCO}

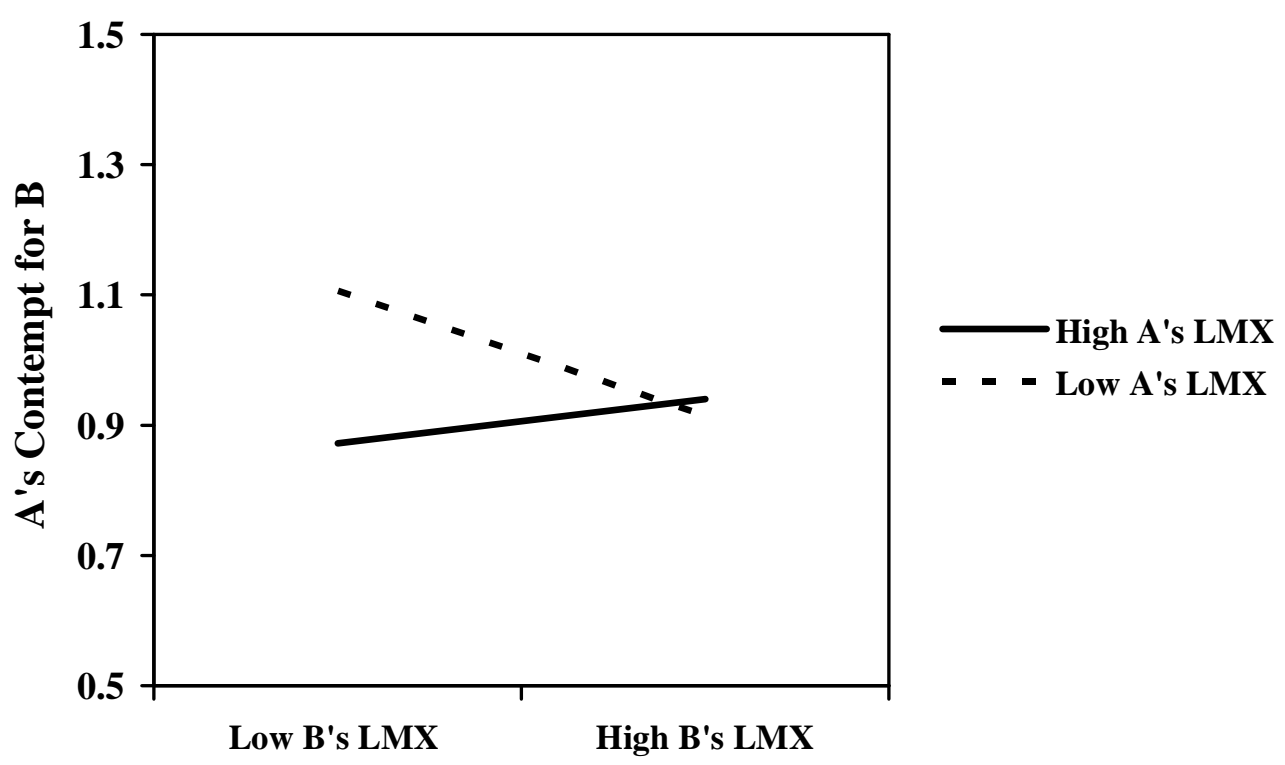

Figure 2. Three-way interaction between coworker A's LMX, coworker B's LMX, and SCO on A's contempt for B (Study 1). LMX = leader-member exchange; SCO = social comparison orientation. 


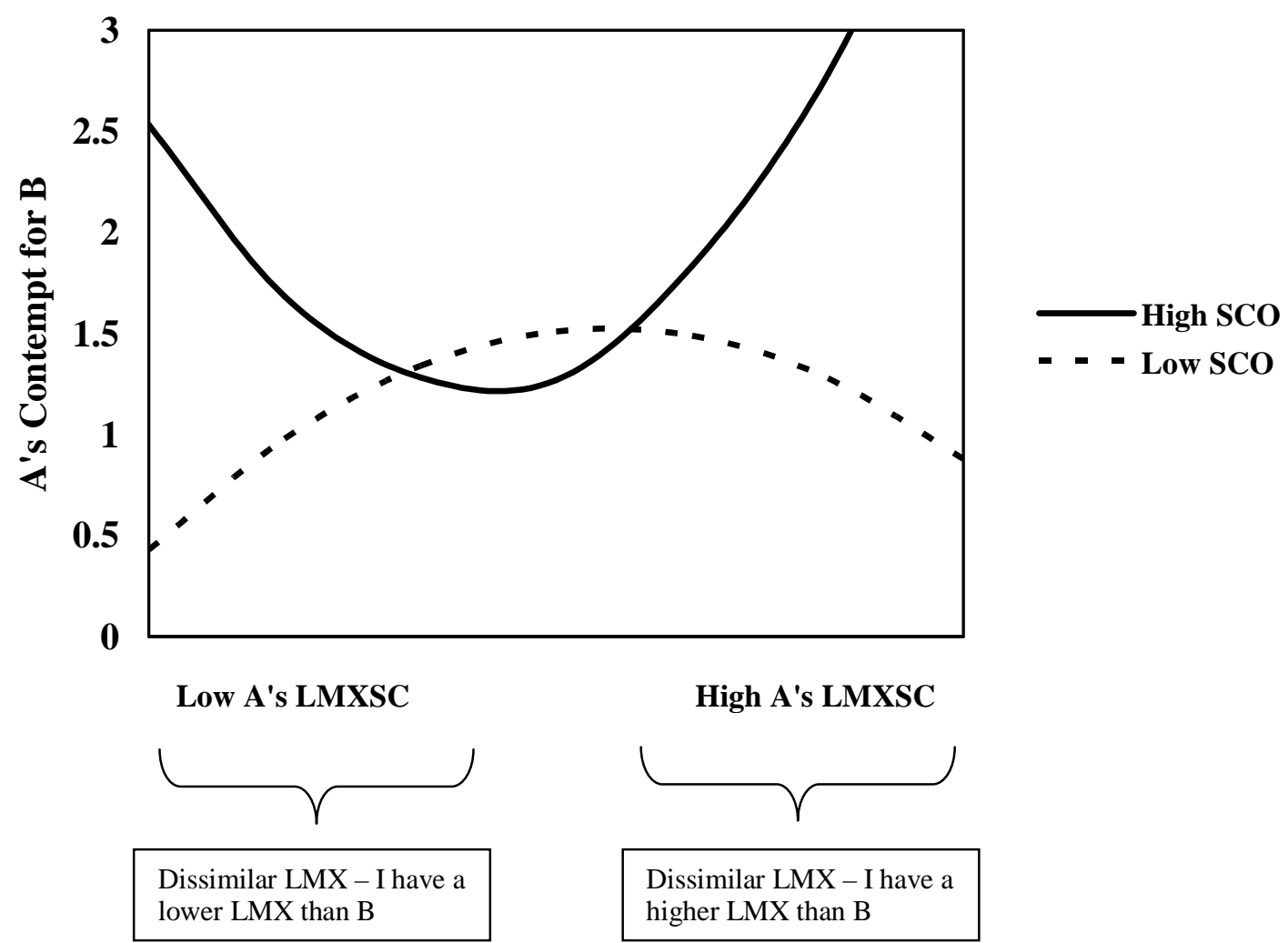

Figure 3. Curvilinear interactive relationship between A's LMXSC and SCO on A's contempt for B (Study 2). LMX = leader-member exchange; LMXSC = LMX social comparison; $\mathrm{SCO}=$ social comparison orientation . 